NIST Advanced Manufacturing Series 100-43

\title{
Inert Gas Flow Speed Measurements in Laser Powder Bed Fusion Additive Manufacturing
}

Jordan S. Weaver

Alec Schlenoff

David C. Deisenroth

Shawn P. Moylan

This publication is available free of charge from:

https://doi.org/10.6028/NIST.AMS.100-43

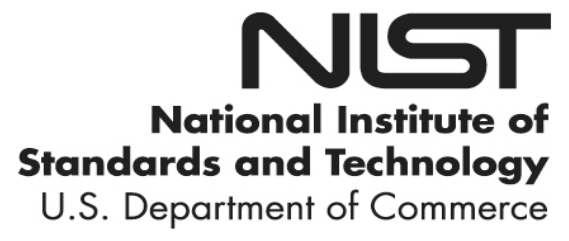




\title{
Inert Gas Flow Speed Measurements in Laser Powder Bed Fusion Additive Manufacturing
}

\author{
Jordan S. Weaver \\ Alec Schlenoff \\ David C. Deisenroth \\ Shawn P. Moylan \\ Intelligent Systems Division \\ Engineering Laboratory
}

This publication is available free of charge from:

https://doi.org/10.6028/NIST.AMS.100-43

October 2021

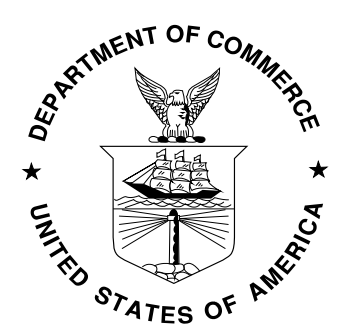

U.S. Department of Commerce

Gina M. Raimondo, Secretary

National Institute of Standards and Technology James K. Olthoff, Performing the Non-Exclusive Functions and Duties of the Under Secretary of Commerce for Standards and Technology \& Director, National Institute of Standards and Technology 
Certain commercial entities, equipment, or materials may be identified in this document in order to describe an experimental procedure or concept adequately. Such identification is not intended to imply recommendation or endorsement by the National Institute of Standards and Technology, nor is it intended to imply that the entities, materials, or equipment are necessarily the best available for the purpose.

National Institute of Standards and Technology Advanced Manufacturing Series 100-43

Natl. Inst. Stand. Technol. Adv. Man. Ser. 100-43, 24 pages (October 2021)

This publication is available free of charge from: https://doi.org/10.6028/NIST.AMS.100-43 


\begin{abstract}
Laser powder bed fusion (LPBF) is an additive manufacturing technology that uses a laser to selectively melt powder feedstock to build parts in a layer-by-layer process. For metals-based LBPF additive manufacturing, the interaction of the laser and powder feedstock creates byproducts such as a plume, spatter, and powder ejecta. Directional gas flow, typically nitrogen or argon, is used to remove or mitigate the negative effects of these byproducts. This report documents and presents gas flow measurements using hot-wire anemometers (HWA) for two different nozzles on a commercial LPBF machine and two different gasses at the NIST Additive Manufacturing Metrology Testbed (AMMT). The AMMT gas flow system generates comparable volumetric flow rates with argon and with nitrogen, which result in comparable flow speed profiles for both gasses. There are significant differences in the gas speed profiles along the gas flow direction (Y-position) and minimal differences perpendicular to the gas flow direction (X-position) with both machines. The speed differences with Y-position are in part due to the elevated inlet and outlet nozzles from the build platform. The average speed only decreases slightly from the inlet to the outlet despite these differences in the speed profiles. The grid nozzle on the commercial machine with a downward facing row of channels at the base of the nozzle increases the gas speed close to the build platform; however, non-uniform speed profiles remain. Gas speed and therefore gas speed measurements with HWAs are highly dependent on $\mathrm{Z}$ and $\mathrm{Y}$ position. This should be considered when prescribing machine performance protocols. Additional suggestions for measuring and reporting gas flow are made as well as recommended future experiments and simulations to assist in machine performance standards.
\end{abstract}

\title{
Key words
}

Hot-wire anemometer; gas flow speed; machine performance; plume; spatter; qualification; additive manufacturing. 


\section{Table of Contents}

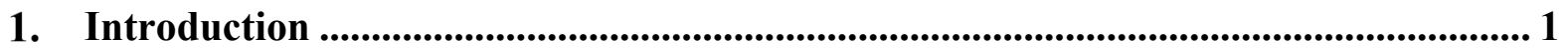

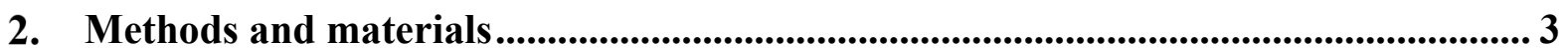

2.1. Experiment setup and measurements ............................................................... 3

2.2. Application of air HWAs to nitrogen and argon .................................................. 7

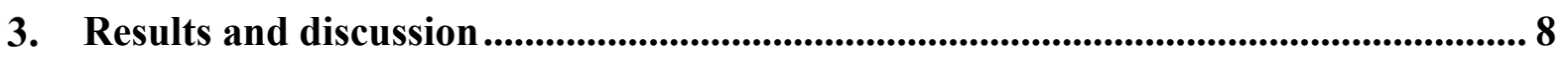

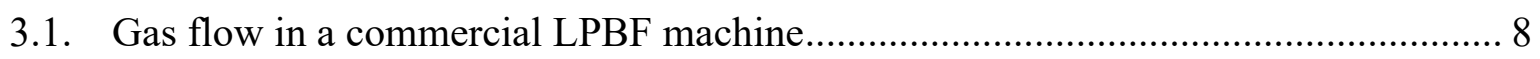

3.2. Gas flow at the NIST Additive Manufacturing Metrology Testbed ......................... 13

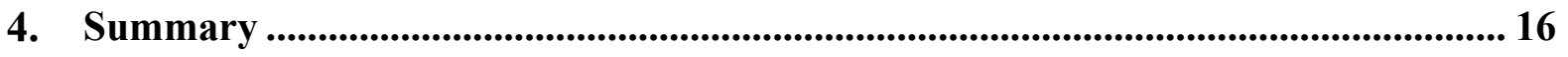

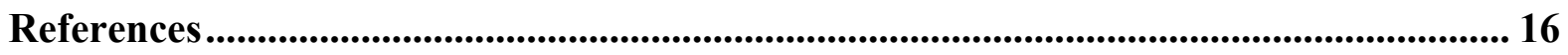

\section{List of Tables}

Table 1. Gas flow measurement methods applied to LPBF

Table 2. Average temperature measurements for commercial machine Z-positions (height above the heated build platform). The uncertainty $(\mathrm{k}=1)$ for $Z$-positions is assumed to be $\pm 1 \mathrm{~mm}$. Each measurement for a fixed Z-position was taken at a different XY-position (minimum of $10 \mathrm{XY}$-positions).

\section{List of Figures}

Fig. 1. (a) inlet face of the standard nozzle (b) inlet face of the grid nozzle, (c) side view of the grid nozzle showing the downward projection of gas for the bottom row of channels, and (d) cross-sectional illustration of the AMMT inlet nozzle...

Fig. 2. (a) commercial machine build chamber with anemometer setup: hot-wire anemometers (HWA) and Z-stage suspended from crossbars (b) rear wall of build chamber showing upper and lower (nozzle) inlets, and (c) close up of measurement setup with three HWAs staggered. HWAs and build platform are not in final positions in this image. The thermocouple is not shown. The gas outlet is also not shown in these images.

Fig. 3. Modified Akima piecewise cubic Hermite interpolation (makima) of gas flow speed measurements. White circles are the locations (300) of measurements. (a) five YZ planes and (b) six XZ planes See Fig. 4 for data plotted with confidence intervals. 10

Fig. 4. (a) schematic of the commercial machine build area and the locations of the six plots at different $Y$-positions (b-g) of Z-position versus gas speed with the standard nozzle. Data points are the average \pm confidence intervals $(p=68.3 \%)$.

Fig. 5. Average gas speed versus Y-position. The five gas speed profiles in the X-direction from $4.1 \mathrm{~mm}$ to $36.1 \mathrm{~mm}$ in Z-position are averaged at each Y-position. Data points are the average \pm confidence intervals ( $p=95 \%)$. Confidence intervals $(p=95 \%)$ for the Yposition are estimated at $\pm 5 \mathrm{~mm}$ based on setup/positioning errors.

Fig. 6. (a) schematic of the commercial machine build area and the locations of three plots at different $\mathrm{Y}$-positions along the $\mathrm{X}$-centerline (b-d) comparing the Z-position vs. gas speed for 
the standard and grid nozzle. Data points are the average \pm confidence intervals $(p=$ $68.3 \%)$

Fig. 7. (a) schematic of the AMMT build area and the locations of four Y-positions (b-d) of $\mathrm{Z}$-position versus nitrogen $\left(\mathrm{N}_{2}\right)$ flow speed and two $\mathrm{Y}$-positions (b-d) of Z-position versus argon (Ar) flow speed. Each speed profile is taken at $\mathrm{X}=0 \mathrm{~mm} . \alpha=$ proportional valve setting. Data points are the expected value \pm confidence intervals $(p=68.3 \%) \ldots \ldots \ldots \ldots \ldots . . .15$ 


\section{Introduction}

Laser powder bed fusion (LPBF) is an additive manufacturing technology that uses a laser to selectively melt powder feedstock in order to build parts in a layer-by-layer process. For metals-based LPBF, the interaction of the laser and powder feedstock creates byproducts such as a plume (evaporated metal that condenses into small, suspended nanoparticles), spatter (material ejected from the molten pool), and powder ejecta (gas/vapor entrained powder not fused to the part). These byproducts, and the importance of directional gas flow to remove and mitigate their effects, have been recognized in laser welding. Kamimuki et al. [1] showed that pores and spatter decreased while penetration depth increased with an optimized side gas flow; Fabbro et al. [2] demonstrated the dependence of the plume droplet generation process on laser scan speed; Zou et al. [3] showed with experiments and calculations that suspended particles in the plume cause laser beam attenuation resulting in wider and shallower welds; and Nakamura et al. [4] studied how laser speed influences the size and exit location of spatter from the melt pool. This knowledge has also been applied to LPBF to improve gas flow and part performance.

One of the guiding principles for gas flow in LPBF is uniformity. A non-uniform gas flow across the build area could result in part properties that depend on the build location due to differences in byproduct removal. Ferrar et al. [5] used computations to improve the gas flow delivery system with a more uniform velocity field. Experiments before and after improvements showed more uniform part properties (a decrease in the standard deviation) across the build platform. Chen et al. [6] and Philo et al. [7] also showed that changes to inlet nozzle designs can improve flow speed uniformity using computation fluid dynamics (CFD). Lastly, Chen and Wang evaluated the performance of two different inlet nozzles using particle image velocimetry for measurements and flow uniformity as an evaluation criterion [8].

Laser scan direction relative to gas flow direction has a significant influence on the process. Anwar and Pham [9] studied the difference between the laser scanning opposite and with the direction of gas flow. They found that parts built when the laser scans with the direction of gas flow have lower ultimate tensile strength. This was explained by the fact that the plume byproducts suspended in the gas flow in the laser scan direction, and this causes more porosity defects due to the attenuation, scattering, and/or distortion of the laser beam. Anwar and Pham also observed less spatter accumulation at the outlet when the laser scan direction was with the gas flow direction since the spatter is blown into the laser.

Increasing the gas speed typically improves part performance. Anwar and Pham [9] showed that an increase from $30 \%$ to $60 \%$ of the machine's maximum gas speed increases part ultimate tensile strength and the amount of powder collected at the outlet. Shen et al. [10] showed that higher gas speeds eliminate porosity defects, and an upper limit on gas speed exists when the powder layer is visibly disturbed leading to layer fluctuations and defects. Reijonen et al. [11] found that increasing gas speed resulting in reduced porosity holds true for a wide range of laser power and scan speed combinations. They also demonstrated the effect of gas speed on the melt pool morphology of single- 
track laser scans. Lastly Ladewig et al. [12] showed that reducing gas flow speed resulted in more redeposition of byproducts on parts and the surrounding powder bed.

There are a few other notable studies that do not fall under the three previous principles of uniformity, laser scan direction, and increasing gas speed. Zheng et al. [13] studied the effect of laser scan speed on vapor plume and spatter generation for a broad range of scan speed during LPBF using high speed imaging. They noted the potential link between plume instability and process instability. Deisenroth et al. [14] showed that melt pool morphology becomes irregular without gas flow along with an increase in the coefficient of variation for inline melt pool monitoring hot spot area. Esmaeilizadeh et al. [15] observed a spatter rich region in the build area furthest from the gas inlets. This increase in spatter led to higher porosity within parts built in the spatter-rich region. The hypothesis to explain the increase in spatter was that the gas flow trapped rather than removed spatter in this region. Lastly Tenbrok et al. [16] studied the interference of the laser plume from one laser affecting another laser in order to establish multi-laser LPBF scan strategies that avoid this type of interference. They noted a correlation between plume propagation and the occurrence of defects in parts. Clearly, gas flow is an important characteristic of machine performance in LPBF systems.

Table 1 summarizes various gas flow measurement techniques that have been used for LPBF machines. There are other methods available (e.g., laser doppler anemometer, ultrasonic anemometer) that have not yet been applied to LPBF applications. Some of these methods (i.e., Schlieren imaging and smoke visualization) are qualitative flow visualizations. For quantitative measurements, hot wire anemometers are a prevalent choice because they do not require the insertion of smoke, oil droplets, or particles (for quantitative particle image velocimetry) and measure the gas speed with better position resolution compared to vane anemometers that sample a large cross-section. This report focuses on documenting procedures for measuring and reporting gas speed in LPBF machines. The dissemination of gas speed measurements for LPBF machines will lead to a better understanding of part variations within a build as well as performance differences between different machines. This report contains results using hot-wire anemometers for two different types of inlet nozzles on a commercial LPBF machine as well as two different gasses at the NIST Additive Manufacturing Metrology Testbed (AMMT). 
Table 1. Gas flow measurement methods applied to LPBF

\begin{tabular}{|l|l|l|}
\hline Method & Qualitative/Quantitative & References \\
\hline Schlieren Imaging & Qualitative & Bidare et al. [17] \\
\hline Vane anemometer & Quantitative & Shen et al. [10] \\
\hline Particle image velocimetry & Quantitative & Chen and Wang [8] \\
\hline $\begin{array}{l}\text { Hot wire or hot film } \\
\text { anemometer }\end{array}$ & Quantitative & $\begin{array}{l}\text { Schniedenharn et al. [18]; } \\
\text { Reijonen et al. [11]; Wang } \\
\text { and Chang [19]; Philo et al. } \\
\text { [7]; Tenbrock et al. [16] }\end{array}$ \\
\hline Smoke visualization & Qualitative & Wang and Chang [19] \\
\hline
\end{tabular}

\section{Methods and materials}

\subsection{Experiment setup and measurements}

An EOS ${ }^{1}$ M290 commercial LPBF machine was used with the standard nozzle and grid nozzle. These two nozzles are options provided by the original equipment manufacturer. Figure 1 shows the inlet faces of the two commercial machine nozzles as well as the AMMT nozzle. The commercial machine standard nozzle has only a few large channels behind an inlet face of many small circular holes in a thin sheet of metal; whereas the grid nozzle has rectangular channels that match the inlet face with a single row of channels at the bottom in a downward projection. The commercial machine gas flow speed or turbine speed is not set by the user but rather fixed for a given material parameter set. In this case, the CobaltChrome MP1 (CoCrMo alloy) material parameter set was used, which creates a differential pressure turbine setting of 58 mbar with nitrogen gas and build platform heating to $80^{\circ} \mathrm{C}$. Note that establishing gas flow conditions on the commercial machine required build platform heating. The build platform material was titanium with a thickness of $25.05 \mathrm{~mm}$.

The AMMT flow volume was set by the proportional valve (PV) that controls flow to the inlet nozzle. As illustrated in Fig. 1d, the AMMT nozzle consists of an array of $3.2 \mathrm{~mm}$ diameter circular channels with a length to diameter ratio of about 15.5. The AMMT build platform temperature was equivalent to the gas temperature at approximately $21.1^{\circ} \mathrm{C}$. In both the commercial machine and AMMT experiments, the build platform had a machined surface (roughness was not quantified) and was leveled and positioned in the recoating plane following typical procedures for a build. The recoating arm was in the left-end position, which is where it is positioned after spreading a layer of powder. Powder was not present during the measurements. The oxygen content of the gas in all

${ }^{1}$ Certain commercial equipment, instruments, or materials are identified in this paper in order to specify the experimental procedure adequately. Such identification is not intended to imply recommendation or endorsement by NIST, nor is it intended to imply that the materials or equipment identified are necessarily the best available for the purpose. 
experiments was less than $0.2 \%$. The chamber pressure is less than $1 \%$ greater than atmospheric pressure of approximately $101.4 \mathrm{kPa}$ in all experiments.

Three hot-wire anemometers (TSI-Alnor 8465) were used to measure the gas speed. The anemometers were calibrated in air at standard conditions of $21.1^{\circ} \mathrm{C}\left(70^{\circ} \mathrm{F}\right)$ and $101.4 \mathrm{kPa}(14.7 \mathrm{psia})$ [20]. The flow speed measurement standard $(\mathrm{k}=1)$ uncertainty in air is $\pm 2.0 \%$ of the reading or $\pm 0.025 \mathrm{~m} \mathrm{~s}^{-1}$, whichever value is larger. The hot-wire anemometers (HWA) are not omnidirectional and were oriented with the reasonable assumption that the gas flow direction is primarily along the Y-axis of the machine (from the back to the front/door). The flow is not strictly along the Y-axis, though, and there may be a velocity component in the Z-direction caused by the flow from the upper inlet nozzle, especially several centimeters above the build platform. Therefore, the measured quantity is referred to as "speed" because the directionality of the velocity vector is not measured. The HWA accuracy decreases outside the temperature range of $18^{\circ} \mathrm{C}$ to $28^{\circ} \mathrm{C}$ (with an additional $0.2 \%$ standard uncertainty per $1^{\circ} \mathrm{C}$ ). A K-type thermocouple was fixed to the side of one HWA with aluminum tape to measure the local gas temperature in the commercial machine experiments.

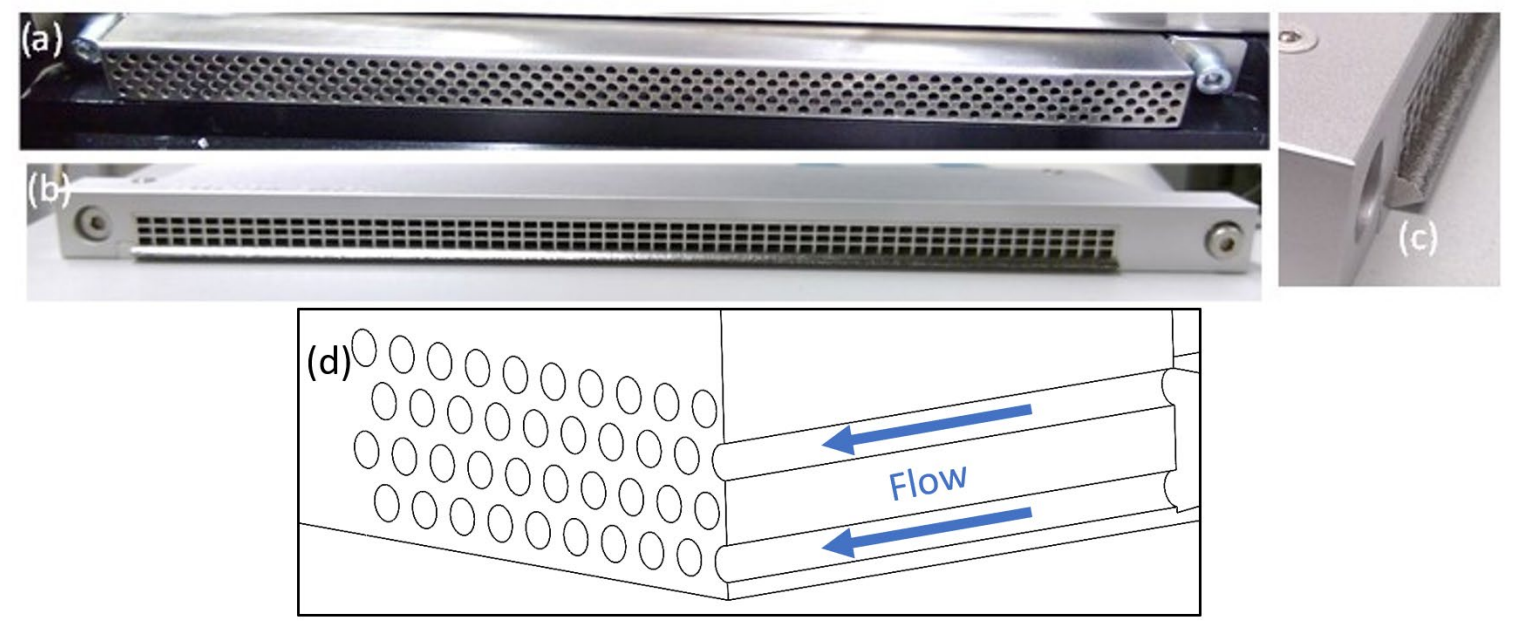

Fig. 1. (a) inlet face of the standard nozzle (b) inlet face of the grid nozzle, (c) side view of the grid nozzle showing the downward projection of gas for the bottom row of channels, and (d) cross-sectional illustration of the AMMT inlet nozzle.

HWAs were attached to a motorized stage that moves along the Z-axis as shown in Fig. 2. The standard uncertainty $(\mathrm{k}=1)$ in $Z$-position was estimated to be $1 \mathrm{~mm}$, which is largely due to establishing and measuring the offset of the HWA from the build platform at its lowest position. The offset was determined by the geometry of the HWA holder, the radius of the HWA shaft, and a feeler gage to measure the gap between the HWA holder and build platform. HWAs were aligned and repositioned several times to measure 30 different predetermined locations over the build area. At each of the 30 locations in the XY plane, 10 measurements were made at different Z-positions using the motorized stage to move the anemometers. The lowest and highest Z-positions relative to the build platform were $4.1 \mathrm{~mm}$ and $46.1 \mathrm{~mm}$, respectively. Measurements $<4 \mathrm{~mm}$ on the commercial machine were not attempted to reduce the heating of the HWA from the 
heated build platform. The speed was recorded three times over the span of 1 minute for each position. Speed data points are the average of the three measurements for the commercial machine and the speed data points at the AMMT are from a single measurement. Confidence intervals $(p=63.5 \%)$ for the speed measurements on the commercial machine were calculated as the root sum squared of the uncertainty of airnitrogen conversion $(1 \%)$, the standard $(\mathrm{k}=1)$ uncertainty of repeated measurements using student $t$-intervals, and the device uncertainty (as described previously). Confidence intervals for the average speed measurements at the AMMT were calculated as the root sum squared with only the uncertainty of air-nitrogen (1\%) or air-argon conversion $(10 \%)$ and the anemometer uncertainty. The air-nitrogen and air-argon conversions are detailed in Section 2.2. The temperature, which affects the HWA uncertainty, was a minimum $\left(26.4^{\circ} \mathrm{C}\right)$ at the highest measured Z-position and a maximum $\left(38.6^{\circ} \mathrm{C}\right)$ at lowest $\mathrm{Z}$ position, closest to the heated build platform. The average temperatures for the $10 \mathrm{Z}$ positions on the commercial machine are provided in Table 2 . The average temperatures for each of the $10 \mathrm{Z}$-positions were determined from a minimum of 10 different XYpositions. The build platform at the AMMT was room temperature (not heated). 

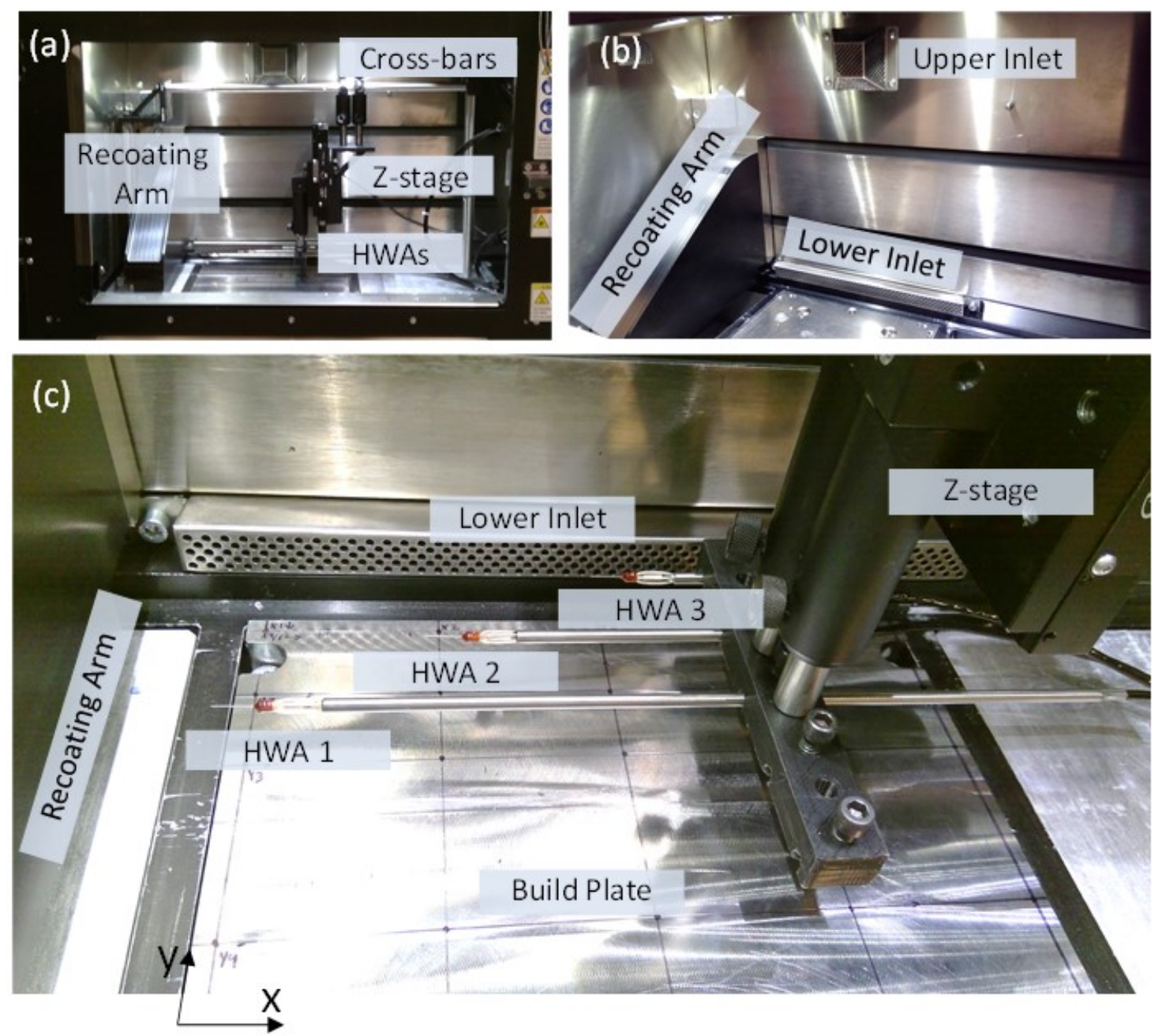

Fig. 2. (a) commercial machine build chamber with anemometer setup: hot-wire anemometers (HWA) and Z-stage suspended from crossbars (b) rear wall of build chamber showing upper and lower (nozzle) inlets, and (c) close up of measurement setup with three HWAs staggered. HWAs and build platform are not in final positions in this image. The thermocouple is not shown. The gas outlet is also not shown in these images. 
Table 2. Average temperature measurements for commercial machine Z-positions (height above the heated build platform). The uncertainty $(\mathrm{k}=1)$ for Z-positions is assumed to be $\pm 1 \mathrm{~mm}$. Each measurement for a fixed Z-position was taken at a different XY-position

(minimum of $10 \mathrm{XY}$-positions).

\begin{tabular}{|c|c|c|c|c|c|c|c|c|c|c|}
\hline $\mathbf{Z}(\mathbf{m m})$ & $\mathbf{4 6 . 1}$ & $\mathbf{3 6 . 1}$ & $\mathbf{3 2 . 1}$ & $\mathbf{2 8 . 1}$ & $\mathbf{2 4 . 1}$ & $\mathbf{2 0 . 1}$ & $\mathbf{1 6 . 1}$ & $\mathbf{1 2 . 1}$ & $\mathbf{8 . 1}$ & $\mathbf{4 . 1}$ \\
\hline $\begin{array}{c}\text { Temperature } \\
\left({ }^{\circ} \mathbf{C}\right)\end{array}$ & 26.4 & 26.6 & 26.7 & 27.0 & 27.3 & 27.9 & 28.8 & 29.8 & 31.6 & 38.6 \\
\hline $\begin{array}{c}\text { Standard } \\
\text { deviation }\left({ }^{\circ} \mathbf{C}\right)\end{array}$ & 1.03 & 0.98 & 0.93 & 0.89 & 1.00 & 1.10 & 1.11 & 1.32 & 2.14 & 3.86 \\
\hline $\begin{array}{c}\text { Number of } \\
\text { measurements }\end{array}$ & 10 & 10 & 10 & 10 & 10 & 10 & 10 & 22 & 22 & 16 \\
\hline
\end{tabular}

\subsection{Application of air HWAs to nitrogen and argon}

The wire of an HWA is heated by passing a current through a resistive element in the wire, which causes the temperature to rise. The electrical resistance of the wire is temperature dependent and as gas flows across the wire, the temperature is reduced. Thus, the wire resistance is the value that is calibrated against gas flow speed. As stated previously, the HWAs are calibrated in air at standard conditions of $21.1{ }^{\circ} \mathrm{C}$ and $101.4 \mathrm{kPa}$. The different thermal properties of gasses other than air will therefore cause incorrect speed measurements, so a correction factor is required to convert the indicated speed to the actual speed. The relation between the flow speed $(V)$, indicated speed $\left(V_{\text {ind }}\right)$, and correction factor $(C)$ are shown in Equation (1).

$$
V=C V_{\text {ind }}
$$

The average heat transfer coefficient on the surface of the wire $(\bar{h})$ is related to the average heat flux from the surface of the wire $\left(\overline{q^{\prime \prime}}\right)$, the average surface temperature of the wire $\left(\overline{T_{w}}\right)$, and the bulk gas temperature $\left(\overline{T_{g}}\right)$ through Equation $(2)$. The average heat flux from the surface of the wire is proportional to its resistance. The resulting wire resistance (based on wire temperature) is calibrated to air speed, which changes the heat transfer coefficient. Therefore, for a given heat transfer coefficient, the anemometer will indicate a corresponding air flow speed whether that heat transfer coefficient is generated by air or another gas. Hence, a relation between speed and heat transfer coefficient is needed to convert the anemometer indicated speed to actual speed for gasses other than air.

$$
\bar{h} \equiv \frac{\overline{q^{\prime \prime}}}{\overline{T_{w}}-\overline{T_{g}}}
$$

The wire diameter is approximately 20 times smaller than its length, so it can reasonably be treated as an infinite cylinder in cross flow. For fluid and flow conditions of $\operatorname{Pr} \gtrsim 0.7$ 
and $40 \leq R e_{D} \leq 4000$ (quantities defined in Equation (5) and Equation (4), respectively), the average wire surface heat transfer coefficient is correlated with flow speed through the diametric Reynolds number $\left(R e_{D}\right)$ as shown in Equation (3) [21].

$$
\bar{h}=\frac{0.683 k \operatorname{Re}_{D}^{0.466} \operatorname{Pr}^{1 / 3}}{D}
$$

In Equation (3), $k$ is the gas thermal conductivity and $D$ is the wire diameter. The $R e_{D}$ is related to gas density $(\rho)$ and dynamic viscosity $(\mu)$ as follows in Equation (4).

$$
R e_{D} \equiv \frac{\rho V D}{\mu}
$$

The Prandtl number is related to the gas specific heat at constant pressure $\left(c_{p}\right)$ as shown in Equation (5).

$$
\operatorname{Pr} \equiv \frac{c_{p} \mu}{k}
$$

Finally, using the nominal properties of air and nitrogen and solving Equation (3) through Equation (5) for equivalent heat transfer coefficients, the nitrogen speed required to generate the same heat transfer coefficient as air is found to result in $C=1.01$ for all flow speeds. As expected, the speeds measured with air and with nitrogen are approximately equivalent, and the measurements applied to nitrogen are assigned an additional $1 \%$ standard measurement uncertainty that are root sum squared with the other speed measurement uncertainties.

Using the same approach for argon, it is found that $C=2.27$. This value was then experimentally verified with air and argon flowing at known speeds, and it was found that the correction factor predicted the argon speed within $\pm 10 \%$, which was within the argon speed uncertainty of the validation experiment. Therefore, the speed correction factor for argon is 2.27 , and the correction factor standard uncertainty is $10 \%$. The correction factors standard uncertainty is root sum squared with the other speed measurement uncertainties.

\section{Results and discussion}

\subsection{Gas flow in a commercial LPBF machine}

The gas speed up to $50 \mathrm{~mm}$ above the commercial machine build area is plotted in Fig. 3. A modified Akima piecewise cubic Hermite interpolation (makima) of the 300 average speed measurements was used in MATLAB to visualize the speed field. White dots mark the locations of HWA measurements. Five YZ planes are shown in Fig. 3a, which correspond to the five X-positions of measurements. The maximum speed (approximately $3.5 \mathrm{~m} \mathrm{~s}^{-1}$ ) occurs at the nozzle about $25 \mathrm{~mm}$ above the build platform. This matches well with to the center height of the nozzle above the build platform, which is $22.5 \mathrm{~mm}$. The maximum speed drops in magnitude and height above the build 
platform as the distance from the nozzle in the Y-direction increases. For example, the maximum gas speed drops to approximately $2 \mathrm{~m} \mathrm{~s}^{-1}$ at a height of $10 \mathrm{~mm}$ and Y-position of $126 \mathrm{~mm}$. From the middle of the build platform $(\mathrm{Y}=126 \mathrm{~mm})$ to the outlet side of the build platform $(\mathrm{Y}=6 \mathrm{~mm})$, the position of the maximum speed increases from $10 \mathrm{~mm}$ to $20 \mathrm{~mm}$ above of the build platform, respectively. This also corresponds to the fact that the bottom of the outlet is positioned $15 \mathrm{~mm}$ above the build platform. The speed fields for the five YZ planes are very similar. Figure $4 \mathrm{~b}$ shows the same data with six $\mathrm{XZ}$ planes corresponding to the six Y-positions of measurements. Again, the speed shows little dependence on the X-position. Not shown or measured is the speed field around the upper inlet nozzle. One of purposes of the upper inlet is to keep the gas from recirculating and sending byproducts toward the laser lens. It is not possible to see recirculation with the current set of measurements, which are limited by the assumption that the primary gas flow direction is along the negative Y-direction. Locations with very low speed near the build platform (near the inlet and outlet) are concerning since this could lead to poor byproduct removal. 


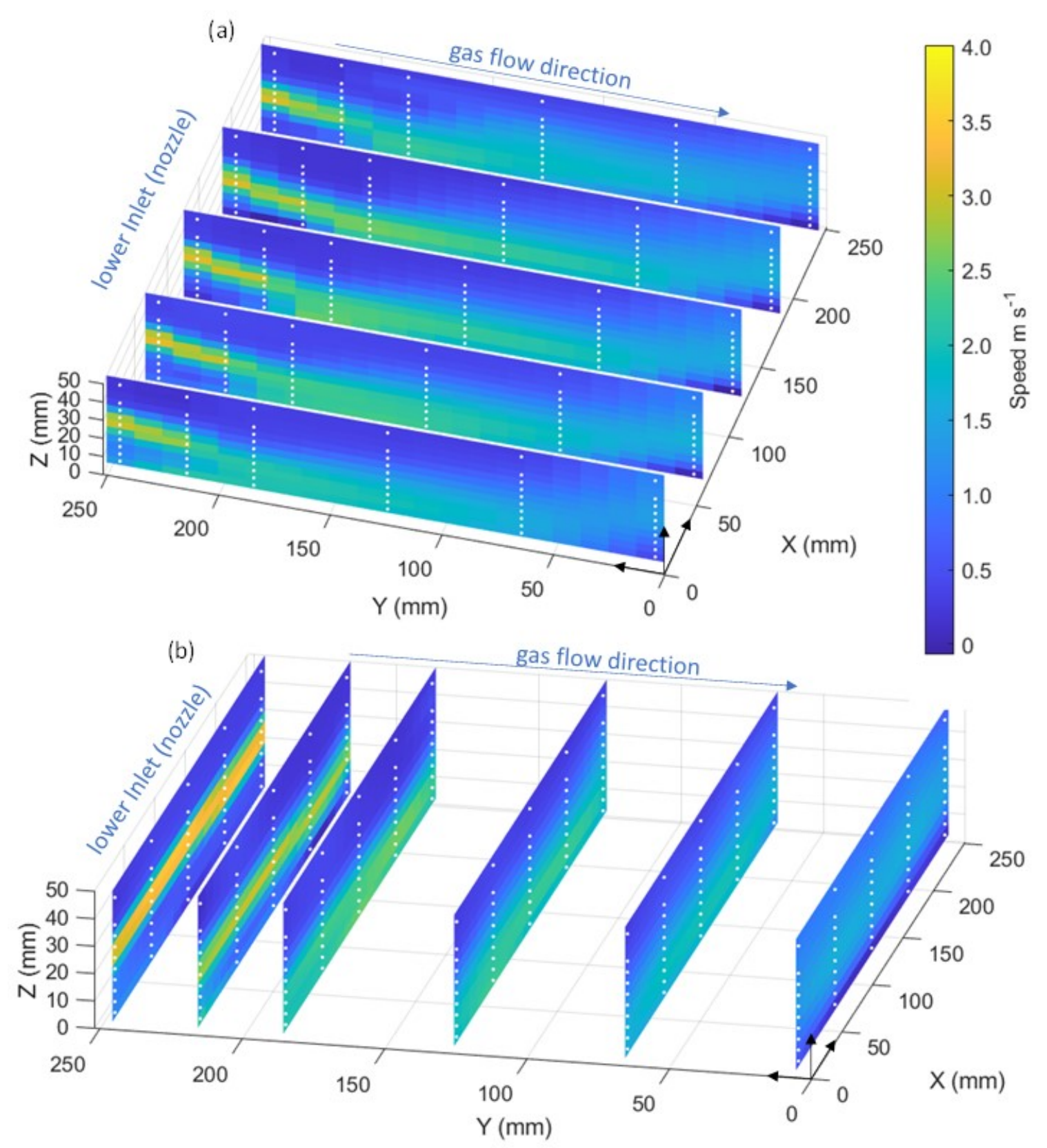

Fig. 3. Modified Akima piecewise cubic Hermite interpolation (makima) of gas flow speed measurements. White circles are the locations (300) of measurements. (a) five YZ planes and (b) six XZ planes See Fig. 4 for data plotted with confidence intervals.

The gas speed profiles (Z-position versus speed) at six different Y-positions are shown in Fig. 4. For each plot at a given Y-position, there are five speed profiles corresponding to five different X-positions. Again, it is apparent that there are only minor differences in gas speed profiles for different X-positions. There are significant differences in the speed profile along the $\mathrm{Y}$-direction with the most significant differences seen at the inlet $(\mathrm{Y}=246 \mathrm{~mm})$ and outlet $(\mathrm{Y}=6 \mathrm{~mm})$ compared to the rest of the build area. The gas speed clearly depends on the height above the build platform and 
distance from the inlet nozzle, and this should be considered when making gas flow measurements.
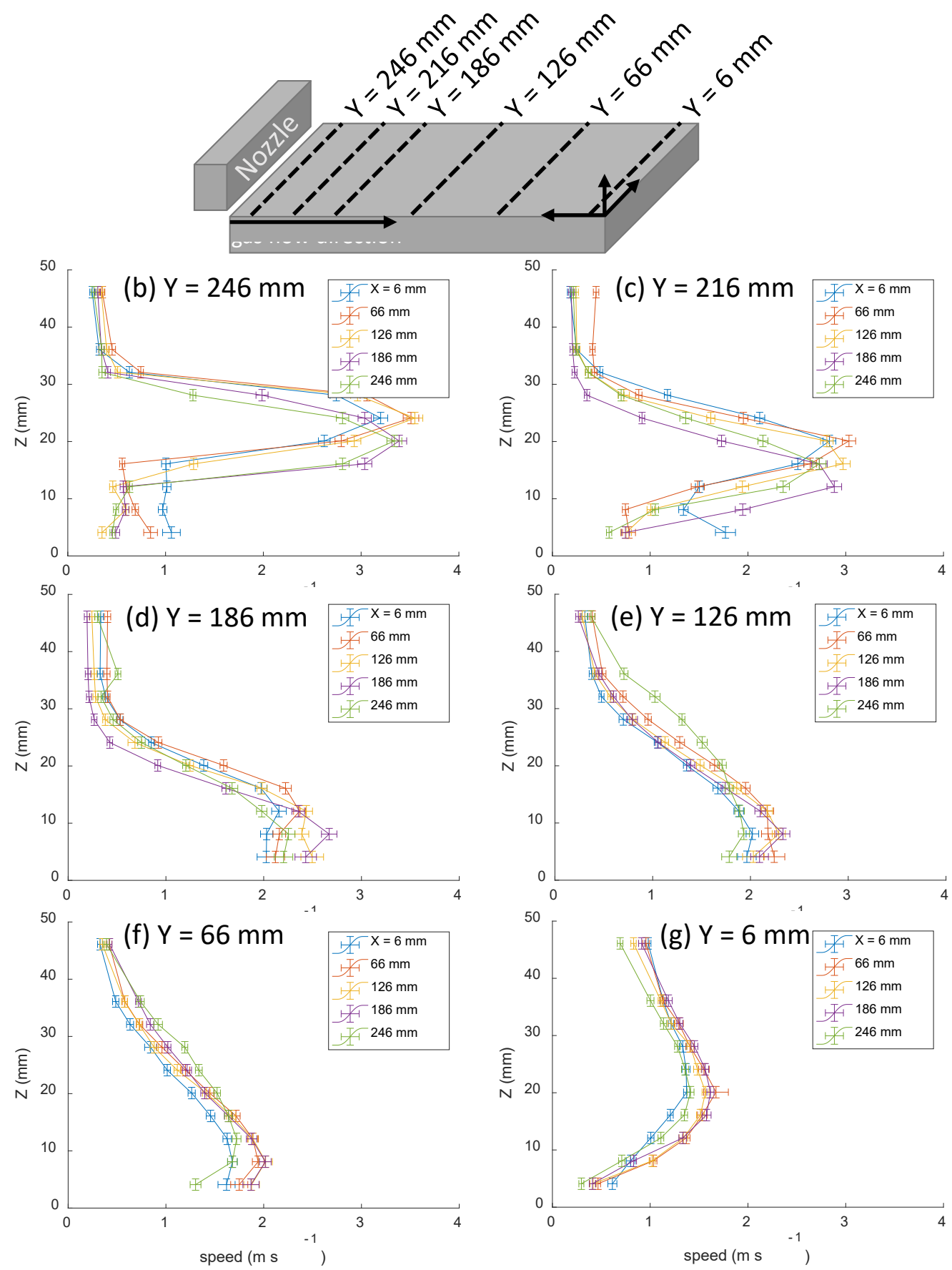

Fig. 4. (a) schematic of the commercial machine build area and the locations of the six plots at different Y-positions (b-g) of Z-position versus gas speed with the standard nozzle. Data points are the average \pm confidence intervals $(p=68.3 \%)$.

One alternative to an HWA is a vane anemometer, which samples over a larger crosssection of gas flow compared to an HWA. Sampling a larger cross-section of gas flow is 
akin to taking an average of the speed profiles. Figure 5 shows the average speed versus Y-position. In this case the average for each Y-position comes from all five X-position speed profiles from a Z-position range of $4.1 \mathrm{~mm}$ to $36.1 \mathrm{~mm}$. This analysis shows that despite significant differences in the speed profiles, the average speed is nearly the same with Y-position. There is only a measurable difference between the average speed near the inlet and outlet with the inlet speed being slightly higher. This suggests that a vane anemometer with an induction diameter of $32 \mathrm{~mm}$ would be a poor choice to measure positional dependence on gas speed. However, because of the averaging effect, a vane anemometer may be a better tool for periodically checking gas speed for machine performance since it would be less sensitive to $\mathrm{Z}$ and $\mathrm{Y}$ positions compared to HWA anemometer measurements.

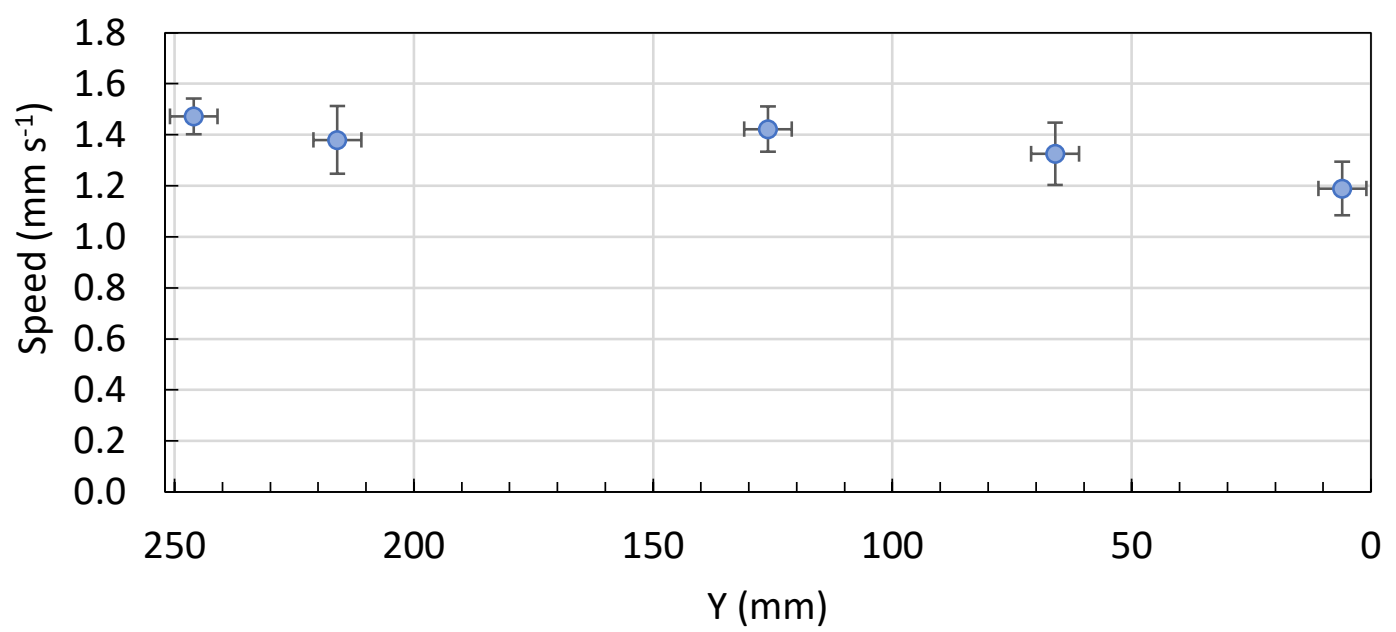

Fig. 5. Average gas speed versus $Y$-position. The five gas speed profiles in the Xdirection from $4.1 \mathrm{~mm}$ to $36.1 \mathrm{~mm}$ in Z-position are averaged at each Y-position. Data points are the average \pm confidence intervals $(p=95 \%)$. Confidence intervals $(p=$ $95 \%$ ) for the Y-position are estimated at $\pm 5 \mathrm{~mm}$ based on setup/positioning errors.

There are two nozzle options for the commercial machine as described in Sec. 2. The grid nozzle is intended to improve the gas flow compared to the standard nozzle. A comparison of the two nozzles for a select number of HWA measurements is provided in Fig. 6. The lower channels on the grid nozzle project down toward the build platform, instead of completely horizontal, which increases the gas speed close to the build platform near the nozzle as seen at $\mathrm{Y}=246 \mathrm{~mm}$ and $\mathrm{Y}=216 \mathrm{~mm}$. The gas speed profiles in the center of the build area, $Y=126 \mathrm{~mm}$, are very similar with slightly lower speeds for the grid nozzle. While this is an improvement, there are still differences in the gas flow profile near the inlet nozzle and the middle of the build area. Uniform gas flow is desirable; however, the exact degree or measure of uniformity required to avoid nonuniform part performance is not known. Further experiments are required to link the gas flow uniformity/non-uniformity to melt-pool size and part performance. Gas flow direction measurements would also provide further insight in the position and nozzle 
design dependence of the gas flow field. Computational fluid dynamic simulations would allow for visualizing the full velocity field.

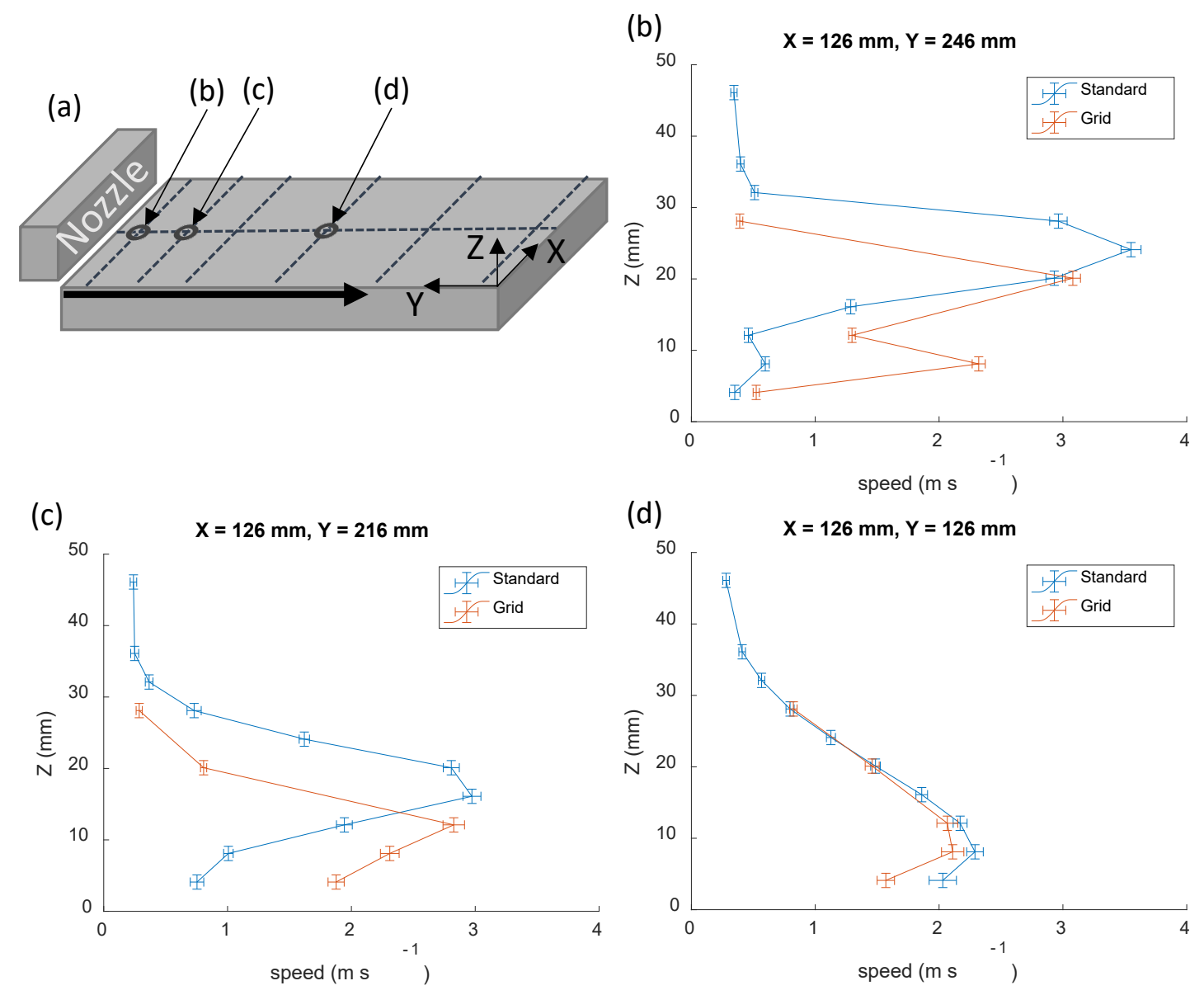

Fig. 6. (a) schematic of the commercial machine build area and the locations of three plots at different $\mathrm{Y}$-positions along the $\mathrm{X}$-centerline (b-d) comparing the Z-position vs. gas speed for the standard and grid nozzle. Data points are the average \pm confidence intervals $(p=68.3 \%)$.

\subsection{Gas flow at the NIST Additive Manufacturing Metrology Testbed}

A comparable measurement approach to that implemented on the commercial LPBF machine was also implemented to characterize the gas flow speed on the NIST AMMT. As shown in Fig. 7a, a different coordinate system was used, with the origin in the center of the build area. The AMMT gas flow speed is adjustable by changing the opened area of the main PV orifice, measured in percentage. Five proportional valve (PV) settings, $\alpha$, were used with two different gasses: nitrogen and argon as shown in Fig. 7 (b-e) and Fig. 7 (f-g), respectively. Each speed profile is taken at $\mathrm{X}=0 \mathrm{~mm}$ measured from the coordinate system shown in Fig. 7a. Several supplementary measurements confirm that the X-direction gas flow profile uniformity is approximately as uniform as the commercial machine and so the central flow profile at $\mathrm{X}=0 \mathrm{~mm}$ is representative of the flow profiles across the build area at each Y position. 
With $\alpha=30 \%$, the nitrogen gas flow speed profile is approximately equivalent to the commercial machine flow profile near the central Y positions of the build area. More specifically, the AMMT profile at $\mathrm{Y}=30 \mathrm{~mm}$ is comparable to that of the commercial machine at $\mathrm{Y}=186 \mathrm{~mm}$, the AMMT profile at $\mathrm{Y}=5 \mathrm{~mm}$ is comparable to that of the commercial machine at $\mathrm{Y}=126 \mathrm{~mm}$, and the AMMT profile at $\mathrm{Y}=-20 \mathrm{~mm}$ is comparable to that of the commercial machine at $\mathrm{Y}=66 \mathrm{~mm}$.

The AMMT inlet nozzle is located closer to the build platform (bottom of the nozzle at $Z$ $=4 \mathrm{~mm}$ ) than the commercial machine, and the nozzle is recessed from the build area by $25 \mathrm{~mm}(\mathrm{Y}=75 \mathrm{~mm})$ in order to allow the flow to partially develop before reaching the build area. The location of the nozzle on AMMT helps to mitigate the low-speed flow that occurs in the build area near the standard nozzle of the commercial machine. The center of the nozzle is located at approximately $Z=12 \mathrm{~mm}$, which corresponds to the peak speed of each profile, which falls between $Z=5 \mathrm{~mm}$ and $Z=15 \mathrm{~mm}$ in each case. As shown by the difference between the standard nozzle and the grid nozzle of the commercial machine, higher flow speeds closer to the build platform are preferable, which was achieved by the AMMT at $\mathrm{Y}=55 \mathrm{~mm}$ with nitrogen and $\alpha=30 \%$.

Increasing the proportional valve setting increases the gas flow speed at each Y position for both gasses. For reference, $\alpha \leq 75 \%$ did not disrupt a $40 \mu \mathrm{m}$ thick layer of typical nickel alloy powder resting on a ground nickel alloy substrate.

The AMMT gas flow system creates an approximately constant volumetric flow rate of gas, and so the velocity profiles developed with nitrogen and argon are quite similar even though argon is approximately $29 \%$ more dense and approximately $29 \%$ more viscous under the conditions tested. The similarity in flow is shown by the profiles at $\mathrm{Y}=30 \mathrm{~mm}$ and $\mathrm{Y}=-20 \mathrm{~mm}$ in Fig. 8c and Fig. 8f and Fig. 8e and Fig. 8g, respectively. The speed measurement uncertainty is significantly larger with argon, as discussed in Sec. 2.2. 


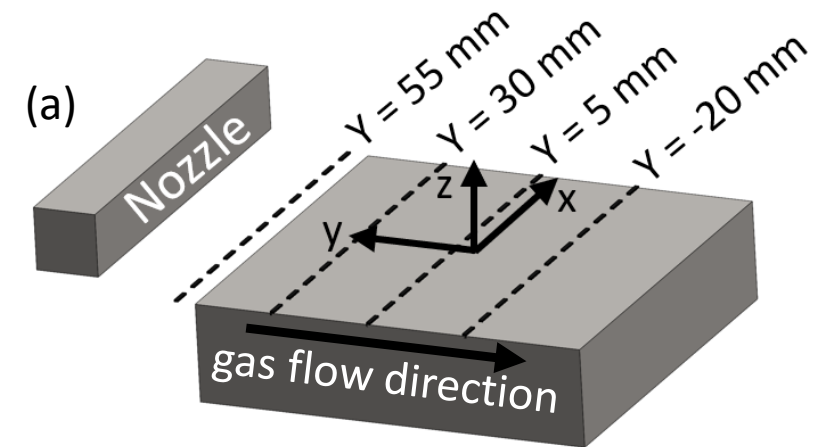

(b) $\mathrm{Y}=55 \mathrm{~mm}, \mathrm{~N}_{2}$

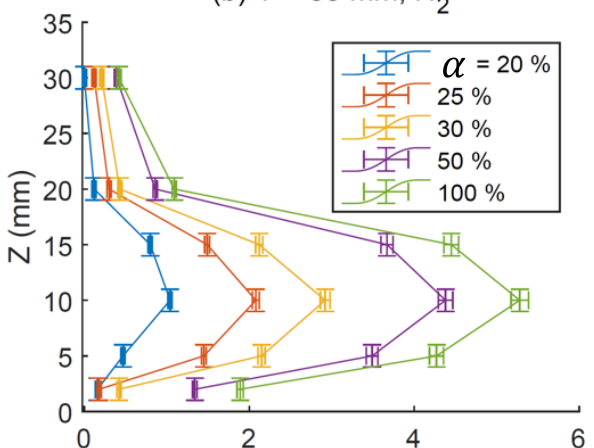

(d) $\mathrm{Y}=5 \mathrm{~mm}, \mathrm{~N}_{2}$

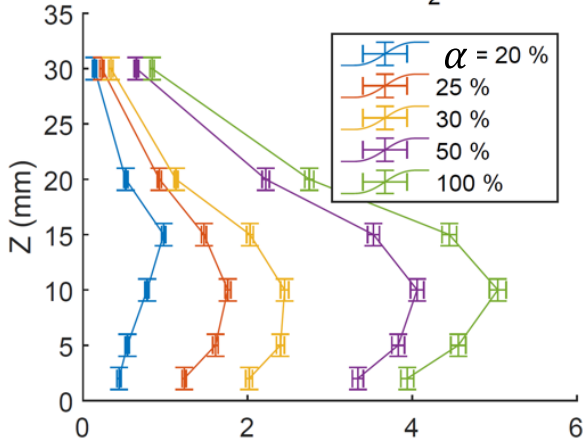

(f) $\mathrm{Y}=30 \mathrm{~mm}, \mathrm{Ar}$

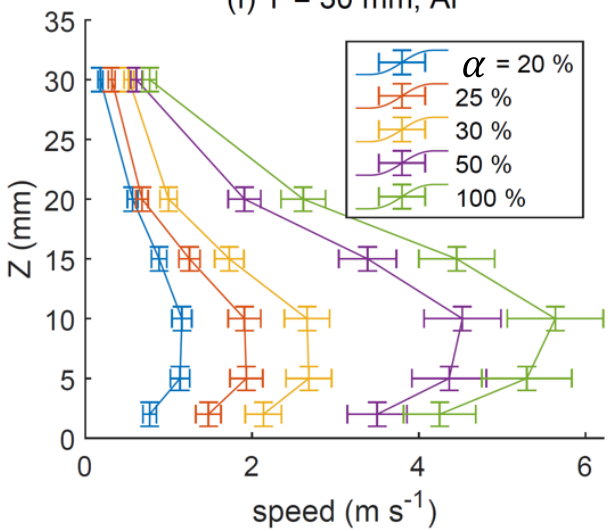

(c) $\mathrm{Y}=30 \mathrm{~mm}, \mathrm{~N}_{2}$

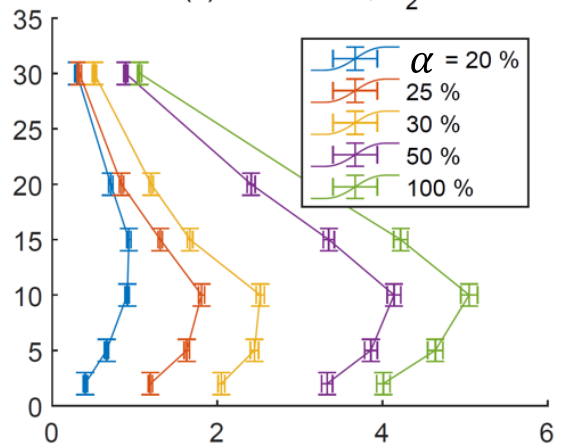

(e) $\mathrm{Y}=-20 \mathrm{~mm}, \mathrm{~N}_{2}$

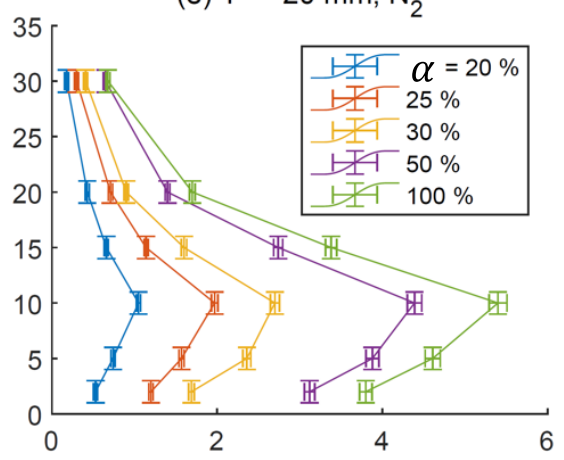

(g) $\mathrm{Y}=-20 \mathrm{~mm}, \mathrm{Ar}$

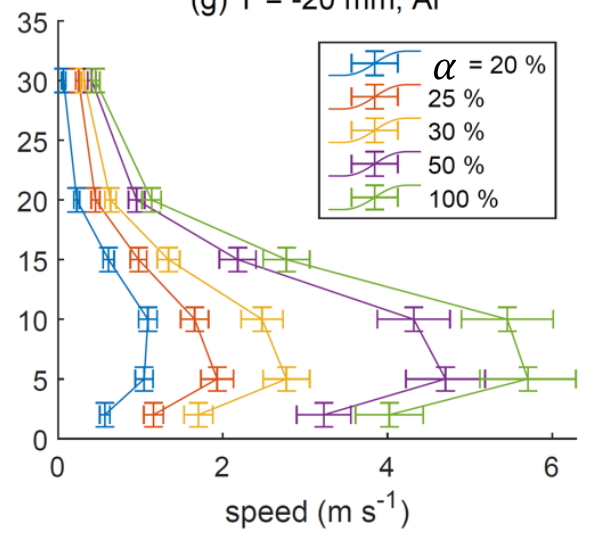

Fig. 7. (a) schematic of the AMMT build area and the locations of four Y-positions (b-d) of Z-position versus nitrogen $\left(\mathrm{N}_{2}\right)$ flow speed and two $\mathrm{Y}$-positions (b-d) of Z-position versus argon (Ar) flow speed. Each speed profile is taken at $\mathrm{X}=0 \mathrm{~mm} . \alpha=$ proportional valve setting. Data points are the expected value \pm confidence intervals ( $p=68.3 \%$ ). 


\section{Summary}

A series of hot-wire anemometer (HWA) measurements were performed on a commercial LPBF machine and the NIST AMMT to determine the gas speed field in the build volume within $50 \mathrm{~mm}$ and $35 \mathrm{~mm}$ above the build platform, respectively. Gas flow speed as a function of the AMMT proportional valve setting was also measured. It was found that the AMMT gas flow system generates comparable volumetric flow rates with argon and with nitrogen, which result in comparable flow speed profiles for both gasses. There are significant differences in the gas speed profiles along the gas flow direction (Yposition) and minimal differences perpendicular to the gas flow direction (X-position) with both machines. The speed differences with Y-position are in part due to the elevated inlet and outlet nozzles from the build platform. The average speed only decreases slightly from the inlet to the outlet despite these differences in the speed profiles. The grid nozzle with a downward facing row of channels at the base of the nozzle increases the gas speed close to the build platform; however, non-uniform speed profiles remain. Gas speed and therefore gas speed measurements with HWAs are highly dependent on Z and Y position. This should be considered when prescribing machine performance protocols. Anemometers that sample a larger cross-section of gas flow (e.g., vane anemometer) would be less sensitive to Y-position as evidenced by the similar average speed across the build platform. This could be more advantageous for periodic measurements of machine performance with less variation due to position/setup. Additional experiments linking the non-uniform speed profiles to melt pool size and part performance would be valuable to understand if the non-uniform speed profiles have a profound effect on byproduct removal and the manufacturing process. Computational fluid dynamic simulations would aid in translating the speed measurements into full velocity field estimates as well as determining the effects of build platform temperature and surface roughness (i.e., other setup variables) on HWA measurements.

\section{References}

[1] Kamimuki K, Inoue T, Yasuda K, Muro M, Nakabayashi T, Matsunawa A (2002) Prevention of welding defect by side gas flow and its monitoring method in continuous wave Nd: YAG laser welding. Journal of Laser applications 14(3):136-145.

[2] Fabbro R, Slimani S, Doudet I, Coste F, Briand F (2006) Experimental study of the dynamical coupling between the induced vapour plume and the melt pool for Nd-Yag CW laser welding. Journal of physics D: Applied physics 39(2):394.

[3] Zou J, Yang W, Wu S, He Y, Xiao R (2016) Effect of plume on weld penetration during high-power fiber laser welding. Journal of Laser Applications 28(2):022003.

[4] Nakamura H, Kawahito Y, Nishimoto K, Katayama S (2015) Elucidation of melt flows and spatter formation mechanisms during high power laser welding of pure titanium. Journal of Laser Applications 27(3):032012.

[5] Ferrar B, Mullen L, Jones E, Stamp R, Sutcliffe CJ (2012) Gas flow effects on selective laser melting (SLM) manufacturing performance. Journal of Materials 
Processing Technology 212(2):355-364.

https://doi.org/https://doi.org/10.1016/j.jmatprotec.2011.09.020

[6] Chen Y, Vastola G, Zhang YW (2018) Optimization of inert gas flow inside laser powder bed fusion chamber with computational fluid dynamics. Proceedings of the 29th Annual International Solid Freeform Fabrication Symposium.

[7] Philo A, Sutcliffe C, Sillars S, Sienz J, Brown S, Lavery N (2020) A study into the effects of gas flow inlet design of the Renishaw AM250 laser powder bed fusion machine using computational modelling. Solid Freeform Fabrication 2017: Proceedings of the 28th Annual International Solid Freeform Fabrication Symposium-An Additive Manufacturing Conference, SFF 2017, pp 1203-1219.

[8] Chen X-X , Wang W-C (2020) The applications of particle image velocimetry (PIV) to experimentally observe the flow behaviors inside the Selective Laser Melting (SLM) working chamber. Flow Measurement and Instrumentation 73:101738. https://doi.org/https://doi.org/10.1016/i.flowmeasinst.2020.101738

[9] Anwar AB, Pham Q-C (2017) Selective laser melting of AlSi10Mg: Effects of scan direction, part placement and inert gas flow velocity on tensile strength. Journal of Materials Processing Technology 240:388-396.

[10] Shen H, Rometsch P, Wu X, Huang A (2020) Influence of Gas Flow Speed on Laser Plume Attenuation and Powder Bed Particle Pickup in Laser Powder Bed Fusion. JOM 72(3):1039-1051. https://doi.org/10.1007/s11837-020-04020-y

[11] Reijonen J, Revuelta A, Riipinen T, Ruusuvuori K, Puukko P (2020) On the effect of shielding gas flow on porosity and melt pool geometry in laser powder bed fusion additive manufacturing. Additive Manufacturing 32:101030. https://doi.org/https://doi.org/10.1016/j.addma.2019.101030

[12] Ladewig A, Schlick G, Fisser M, Schulze V, Glatzel U (2016) Influence of the shielding gas flow on the removal of process by-products in the selective laser melting process. Additive Manufacturing 10:1-9. https://doi.org/https://doi.org/10.1016/j.addma.2016.01.004

[13] Zheng H, Li H, Lang L, Gong S, Ge Y (2018) Effects of scan speed on vapor plume behavior and spatter generation in laser powder bed fusion additive manufacturing. Journal of Manufacturing Processes 36:60-67.

[14] Deisenroth DC, Neira J, Weaver J, Yeung H (2020) Effects of Shield Gas Flow on Meltpool Variability and Signature in Scanned Laser Melting. ASME 2020 15th International Manufacturing Science and Engineering Conference, (V001T01A017). https://doi.org/10.1115/msec2020-8410

[15] Esmaeilizadeh R, Ali U, Keshavarzkermani A, Mahmoodkhani Y, Marzbanrad E, Toyserkani E (2019) On the effect of spatter particles distribution on the quality of Hastelloy X parts made by laser powder-bed fusion additive manufacturing. Journal of Manufacturing Processes 37:11-20. https://doi.org/https://doi.org/10.1016/j.jmapro.2018.11.012

[16] Tenbrock C, Kelliger T, Praetzsch N, Ronge M, Jauer L, Schleifenbaum JH (2021) Effect of laser-plume interaction on part quality in multi-scanner Laser Powder Bed Fusion. Additive Manufacturing 38:101810. https://doi.org/https://doi.org/10.1016/j.addma.2020.101810 
[17] Bidare P, Bitharas I, Ward RM, Attallah MM, Moore AJ (2018) Fluid and particle dynamics in laser powder bed fusion. Acta Materialia 142:107-120. https://doi.org/https://doi.org/10.1016/j.actamat.2017.09.051

[18] Schniedenharn M, Wiedemann F, Schleifenbaum JH (2018) Visualization of the shielding gas flow in SLM machines by space-resolved thermal anemometry. Rapid Prototyping Journal.

[19] Wang W-C , Chang C-Y (2017) Flow analysis of the laminated manufacturing system with laser sintering of metal powder. Part I: flow uniformity inside the working chamber. The International Journal of Advanced Manufacturing Technology 92(1):1299-1314. https://doi.org/10.1007/s00170-017-0213-5

[20] TSI, Inc. (2013) Air velocity transducer model 8455/8465/8475: operator and service manual. (Shoreview, MN).

[21] Bergman TL, Incropera FP, DeWitt DP, Lavine AS (2011) Fundamentals of heat and mass transfer (John Wiley \& Sons). 